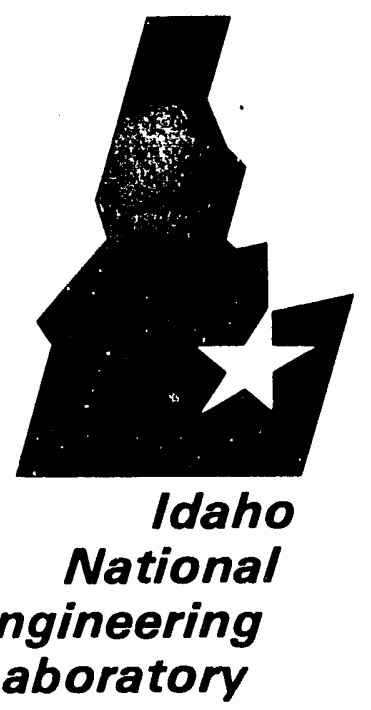

EGG-M-91224

PREPRINT

EGG-M--91224

DE92 003294

\title{
SAFETY CHARACTERISTICS OF OPTIONS FOR PLASMA-FACING COMPONENTS FOR ITER AND BEYOND
}

S. J. Piet, K. A. McCarthy, D. F. Holland, G. R. Longhurst, B. J. Merrili

October 1-3, 1991

14th IEEE Symposium on Fusion Engineering, San Diego

\section{DISCLAIMER}

This report was prepared as an account of work sponsored by an agency of the United States Neither the United States Government nor any agency thereof, nor any of their employees, makes any warranty, express or implied, or assumes any legal liability or responsibility for the accuracy, completeness, or usefulness of any information, apparatus, product, or process disclosed, or represents that its use would not infringe privately owned rights. Reference herein to any specific commercial product, process, or service by trade name, trademark, manufacturer, or otherwise does not necessarily constitute or imply its endorsement, recommendation, or favoring by the United States Government or any agency thereof. The views mendation, or favoring by the Uned herein do not necessarily state or reflect those of the United States Government or any agency thereof.
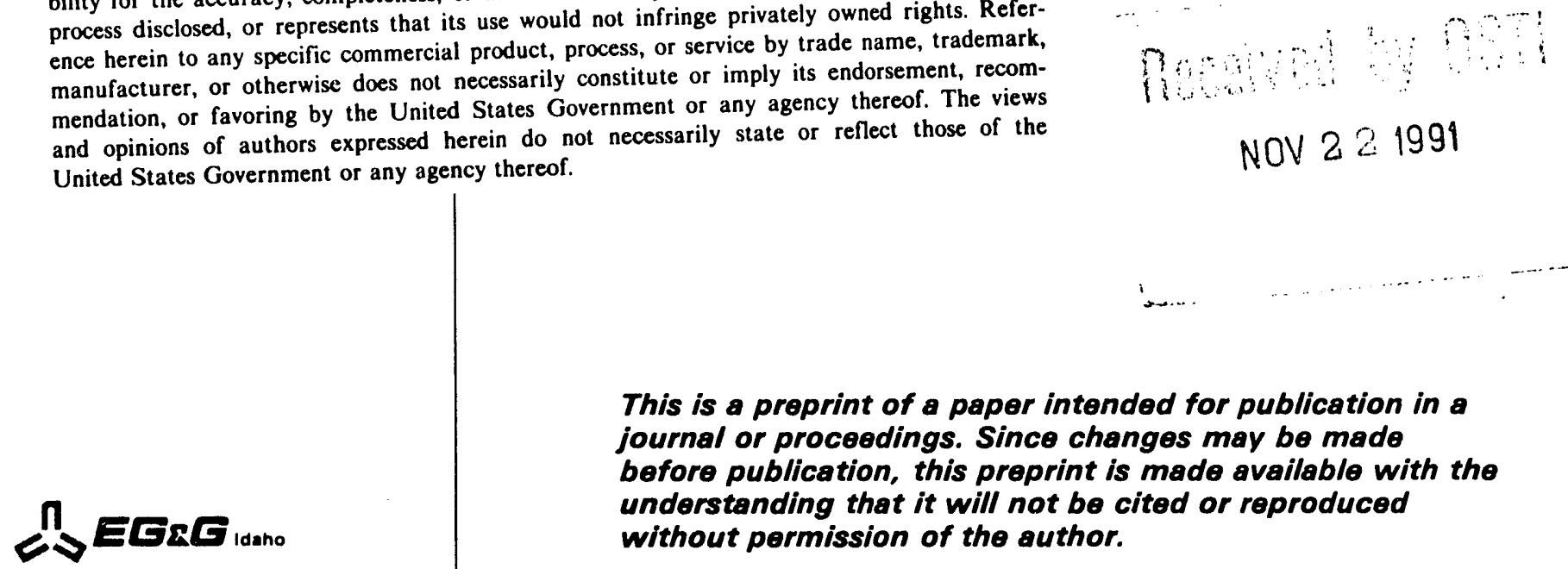

This is a preprint of a paper intended for publication in a journal or proceodings. Since changes may be mado before publication, this preprint is made available with the understanding that it will not be cited or reproduced without permission of the author.

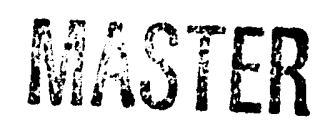




\section{Abstract/Summary}

Plasma-facing components (PFC) likely dominate the safety hazards of the International Thermonuclear Experimental Reactor (ITER) and post-ITER machines. To gain regulatory approval and for fusion energy to fulfill its ultimate attractive safety and environmental potential, safety must be considered when selecting among PFC options. This paper summarizes current PFC safety information.

PFC safety issues fall into seven areas: disruption tolerance, disruption severity, tritium inventory and permeation, accidental energy release, activation/ toxin hazards, cooling disturbances, and system issues. PFC options include current ITER mainline options (Be or $W$ coating, C tiles), variants on current ITER options, and liquid metal (LM) divertors. No PFC option that we have examined is free of critical safety concerns. There are also innovative ideas that may improve any PFC's performance - super-permeable vacuum ducts, helium selfpumping, and gaseous divertors. We conclude with recommendations and a future strategy.

\section{Introduction}

The safety characteristics of a fusion machine can be dominated by PFC choice as shown by both the ITER and ARIES (Advanced Reactor Innovation Evaluation Study) studies.[1,2] The main PFCs are the divertor and first wall (FW), including plasma-side surface material, substrate, and coolant. (Other PFCs not considered here include heating and current drive antennas and diagnostics.) Exposure to high neutron flux and plasma tritium gives PFCs the highest activation product hazard and tritium inventory. Normal operation subjects them to high heat fluxes and thermal and mechanical stresses. They must also withstand some number of plasma disruptions, which produce even higher heat fluxes, induce currents causing severe electromagnetic (EM) forces, and generate energetic runaway electrons with potential to cause severe damage. The safety issues from disruptioninduced failures include subsequent steam/air-PFC chemical reactions, mobilization of in-vessel radioactivity, and need for in-vessel repair/replacements. Besides reduced machine availability, such replacements imply personnel dose, contamination spread, maintenance-equipment failures, and waste generation.

The licensing and attractiveness of ITER dopend on identifying suitable PFCs. [3] ITER will provide the precedent and data base for later machines. Thus, the fusion community must identify the most promising candidates and have PFC experts test them. Here, we help by identifying important safety and environmental PFC issues. Then, we categorize PFC options and innovative ideas.

For each PFC option and innovative idea, we summarize critical safety information. This paper lacks space for a complete discussion of safety issues and up-to-date information. We are now adding to PFC safety information in several areas, including the impact of PFC choice on disruption severity, tritium inventory and permeation, [4] and chemical reactions and activation product mobilization during long-term oxidizing loss of coolant accidents (LOCAs). [5] We plan to publish a comprehensive technical report in the first half of 1992 with these new data. [6]

Based on our most current knowledge and judgement, we rank PFC options for each major area of safety issues. Then, we list the most critical safety issues for PFC options. We end with recommendations and a future strategy.

\section{Safety and Environmental issues}

Table 1 lists the safety and environmental issues for PFCs, grouped to make them easier to grasp. We suggest realistic but challenging goals to help ensure that ITER obtains safety regulatory approval and to contribute to making ITER attractive. We view these goals as preliminary. ITER attractiveness contributes to making later machines (like a DEMO fusion power plant) attractive and to building the case for spending the money for ITER. Designers must strive to minimize safety and environmental hazards, with an As Low As Reasonably Achievable (ALARA) mindset.

Disruptions: Disruption tolerance how a PFC handles given disruption parameters) differs from disruption severity (how choice of PFC material may impact disruption parameters): When ITER operation starts, disruption severity will not be definitively known. Thus, PFC options should be ranked by their tolerance to uncertain disruption parameters.

If the PFC option choice did not impact the disruption parameters themselves, this would adequately compare PFCs for the disruption issue. Yet, JET provides clear evidence that PFC option choice does impact disruption parameters. So, another way to rank PFCs is to consider how the disruption severity changes as one changes PFC material.

Ideally, we would merge "tolerance" and "severity" into a single figure of merit. However, there is presently too little information. For now, the fusion community needs to separately know both tolerance and severity.

Quantifying goals is difficult in both areas since we do not know if mainline PFC options would survive the ITER Conceptual Design Activity (CDA) disruption parameters. Thus, one goal is to select PFC materials so that the disruption severity is no worse than for $C$, which is the basis for the CDA disruption parameters. Carbon may not be an adequate criterion for acceptability since we are not sure if the CDA C-based design will indeed adequately survive disruptions.

The CDA disruption specifications are severe. The time scale for current decay is typically $20 \mathrm{~ms}$, or a current decay rate of $1 \mathrm{MA} / \mathrm{ms}$. The current decay may be "occasionally as short as $5 \mathrm{~ms}$, [7] or $4 \mathrm{MA} / \mathrm{ms}$. More work is needed to show that designs meet the 4 $\mathrm{MA} / \mathrm{ms}$ rate. Yet, this specification may still not be the most energetic (worst) case. Merrill and Jardin estimate that an oxygen ingress from water or air in-leakage might cause current decays as fast as 8 $\mathrm{MA} / \mathrm{ms}$. [8] Disruptions caused by impurity ingress and burn control failures must be considered when specifying worst-case disruption parameters.[3] Erosion of divertor material by disruption heat loads often fixes the divertor 1 ifetime. 
TABLE 1. PFC SAFETY AND ENVIRONMENTAL ISSUES

Safety and Environmental Issue Current goal

\section{Disruption tolerance}

Tolerate EM forces from worst-case current decay rate

Tolerate runaway $300-\mathrm{MeV}$ electron energy density of

Mass loss per disruption

Number of disruptions tolerated

$8 \mathrm{MA} / \mathrm{ms}$ [8]

$30 \mathrm{MJ} / \mathrm{m} 2$ [7]

$1 \mathrm{~kg}$ ? (a)

high (b)

Disruption severity (PFC impact

on disruption parameters)

Current decay rate

Runaway electron current

no worse than carbon no worse than carbon

\section{Iritium inventory and permeation}

Tritium inventory in PFC

Tritium burn fraction in plasma

Tritium permeation rate into coolant

Tritium release during maintenance

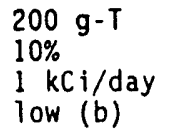

\section{Accidental energy release}

Ene $\cdots$ released in short-term LOCA or LOVA transient

Energy released in long-term LOCA transient

$\mathrm{H} 2$ produced in steam ingress transients

Dust inventory below threshold for dust explosion

\section{No chemical \\ ignition \\ $<$ decay heat}

$10 \mathrm{~kg}-\mathrm{H} 2$

(a)

\section{Activation/toxin hazards}

Mobilization in air/steam

Specific radiological dose (mSv/ $\mathrm{kg}$ )

Tokamak dust inventory

Dust release during maintenance <stetl's (a)

<steel's (a)

$<1 \mathrm{~kg}[1](\mathrm{a})$

low (b)

\section{Cooling disturbances}

Maximum ?ong-term LOCA temperature

Allowable time before damage during LOCA

Time to actively shutdown the plasma

Time to passively shutdown the plasma

Frequency of in-vessel LOCA or LOVA

Frequency of ex-vessel LOCA

Decay heat removable via natural

convection during LOFA

$500 \subset[1]$

\section{$5 \mathrm{~s}$}

1 s $[1,3]$

$1-5$ s [3]

$<1 \mathrm{e}-3 /$ yr $(d)$

$100 \%$

\section{System issues}

Bakeout/conditioning temperature Gamma dose field around ex-vessel coolant piping (personnel dose)

Recycle potential of PFi

$<150 C[1](c)$

$25 \mu \mathrm{Sv} / \mathrm{h}[1]$ high

a. The items marked with (a) must combine to produce a licensable design. This interrelationship makes it difficult to specify separate quantitative goals. Given the toxicity and tritium content of $c, B e, W$, and steel, dust limits of $1 \mathrm{~kg}$ are desiraule. [1]

b. Depends on maintenance scenarios, and associated confinement barriers during maintenance.

c. Temperature limit applies to water PFC coolant. Helium or LM coolants would solve this concern, allowing higher bakeout/conditioning temperatures.

d. In-vessel LOCA frequency of $1 /$ yr may be acceptable from the safety standpoint; however, depending on divertor maintenance/repair schemes, availability considerations probably require a lower goal.
The CDA specification for runaway electrons is al so severe, an energy density of $30 \mathrm{MJ} / \mathrm{m} 2$ from 300 $\mathrm{MeV}$ electrons. [7] The limiting damage criterion seems to be heat deposition in water, raising the water temperature and pressure, [9] potentialiy bursting tubes. We note that helium or LM coolants would relax this water concern, but the potential damage to substrate structures would remain.

We emphasize that more refined models, validated by data, are needed. Disruptions will occur and we must be sure that ITER will tolerate them.

Iritium: The PFC choice may impact the tritium inventory in three ways. First, PFC materials retain tritium. Second, the PFC choice may influence the $0 / T / H e$ recycling of the divertor, hence affecting the tritium burn fraction in the plasma. The burn fraction controls the tritium inventory in most non-PFC fuel cycle components. Third, the PFC fixes the permeation into the divertor and FW coolant.

The total estimated onsite ITER CDA tritium inventory is $5.7 \mathrm{~kg}-T$ during the low fluence, carbon-PFC physics phase and $4.3 \mathrm{~kg}-\mathrm{T}$ during the modest fluence, tungsten-PFC technology phase. These inventories include the PFC, Fuel Cycle, and storage. The tolerable limit for maximum public exposure is an early dose (50-yr committed dose from 7-days exposure) of 100 $\mathrm{mSv}$. The 100-mSv limit applies to worst case accidents; lower limits apply to higher frequency events. The reference ITER release parameters give $0.5 \mathrm{~m} \mathrm{SV} / \mathrm{g}-\mathrm{T}$ released to the environment. [1]

Since the PFC tritium inventory is particularly vulnerable, the tritium inventory goal for PFCs is $200 \mathrm{~g}-\mathrm{T}$. Tritium on or near the PFC material surface could be mobilized during loss of vacuum (LOVA) air ingress or steam ingress from an in-vessel LOCA. Tritium in the PFC bulk material would be mobilized if the material chemically reacts, such as during a long-term worst-case LOCA. As the PFC tritium inventory rises above $200 \mathrm{~g}-\mathrm{T}$, one needs increasingly effective, robust, and costly radioactivity confinement.

The tritium in non-PFC Fuel Cycle systems alone is about $1.6 \mathrm{~kg}-\mathrm{T}$. The ITER CDA tritium burn fraction is about $2.6 \%$. The Fuel Cycle inventory $(1.6 \mathrm{~kg}-\mathrm{T})$ will scale slightly less than linear with burn fraction. If we can increase the tritium burn fraction to $10 \%$ by a combination of physics parameters and engineering solutions, the $1.6 \mathrm{~kg}-\mathrm{T}$ would drop to roughly $500 \mathrm{~g}-\mathrm{T}$. This goal of $10 \%$ seemed reasonable during CDA safety discussions; [1] higher burn fractions are desirable.

We suggest limiting tritium permeation into the divertor and $\mathrm{FW}$ coolants to $1 \mathrm{kCi} /$ day. [7] At this rate, a modest water cleanup system ( $f$ ew MS) would be enough to meet ITER effluent release limits and ALARA requirements. Helium or $L M$ coolants might ease meeting this requirement.

Accidental energy release: There are two different time periods for considering accidental chemical energy release and LOCAs. The first is short-term, with relatively high frequency of occurrence. The second is long-term, with low frequency.

First, during operation, the PFC material will be hot (more so than in current machines). Accidental ingress of air (LOVA) or water (in-vessel LOCA) into the torus will cause chemical reactions, which may release energy, produce $\mathrm{H} 2$ (water only), mobilize tritium or mobilize activation products. Unless the chemical energy release is as high as the operating heat load, the PFC temperatures will drop since air or steam will quench the plasma (probably via a 
disruption). Even for endothermic reactions, there are concerns of $\mathrm{H} 2$ production, tritium mobilization, or activation product/toxin mobilization during this short-term cooldown. For this short-term transient, our goals for chemical energy release are to not trigger chemical ignition nor produce $10 \mathrm{~kg}-\mathrm{H} 2$.

Second, there is a different, long-term problem that has received insufficient attention. If cooling has been disrupted for much of the machine, after the initial cooldown, decay heat will slowly heat up the PFC and other in-vessel components. The CDA assessed the worst-case LOCA temperature as $600 \mathrm{C}+100 \mathrm{C}$ for the $\mathrm{FW}$ and $700 \mathrm{C} \pm 100 \mathrm{C}$ for the divertor, lasting for 1 week. [1] We knew in the CDA that this would mobilize enough $W$ via high temperature oxidation to cause 4.4 Sv early dose to the maximum public individual. Thus, a radioactivity confinement must lower this worst-case dose below the anticipated regulatory dose limit of $100 \mathrm{mSv}$. Yet, we did not realize in the CDA that this week-long oxidizing LOCA would produce significant $\mathrm{H} 2$ for $\mathrm{C}$ or Be PFC. (We are still looking at $W$-steam in this regard.) The CDA goal for limiting $\mathrm{H}_{2}$ production was $10 \mathrm{~kg}-\mathrm{H} 2$ to el iminate the chance of hydrogen explosions in the torus. [1] As a backup (and for other reasons), volumes surrounding the torus are filled with inert gas (He, N2) to inhibit air contact with the torus.[1] Another goal for the long-term transient is that the chemical energy potentially liberated be less than the decay heat, so as not to significantly add to the decay heat problem.

Activation/toxin hazards: We set a goal that the maximum mobilization of activation products be no worse than the amount that would cause a maximum public early dose of $100 \mathrm{mSv}$. This would make ITER passively safe from the activation product viewpoint. From several perspectives, the CDA safety assessment recommended a tokamak dust goal of $\leq 1 \mathrm{~kg}$.[1]

Cooling disturbances: These include in-vessel LOCA, ex-vessel LOCA, and loss of coolant flow (LOFA). More so than for the other PFC safety issues, the response to cooling disturbances is strongly impacted by the substrate and coolant choice besides the PFC surface material.

Table 1 shows a goal for in-vessel LOCA frequency of $1 / \mathrm{yr}$. This is probably acceptable from the safety standpoint. However, depending on the degree of machine damage and the ease of repair, such a frequency may be unacceptable from the standpoint of ITER availability. Since the frequency of in-vessel LOCA or LOVA seems high, the design must provide for as easy and rapid divertor replacement as possible. This may include changing the divertor concept to divertor cassettes that come straight out as a single unit (for each tokamak sector) versus the present complex plate concept. In-situ repairable surfaces like plasmasprayed material appear attractive versus a half-million individual tiles.

Many current tokamaks have had water or air ingresses. With low temperature walls, the damage is limited. However, ITER's PFC surfaces will be much hotter. Thus, contact with oxidizers (water or air) will cause more damage and make vacuum cleanliness more difficult to re-establish. The proper strategy must include maximum ease to repair/replace PFCs and (as noted above) inert gas zones. Changing from water to a non-oxidizing coolant like helium would also offer safety and availability advantages - subject to solving heat transfer and leak-tightness concerns.

System issues: The overpressure from hot water spills during bakeout/conditioning threatens radioactivity confinement.[1] Thus, in the CDA, bakeout/ conditioning of $C$ ( $350 C$ bakeout, 250 C conditioning) and metals $(180 \mathrm{C})$ would not be done with water over 150 C.[1] Thus, some method other than hot water is needed, but not yet developed.

\section{Major safety considerations}

Since PFC safety issues are so severe, it is fortunate we have so many PFC options to consider. Table 2 categorizes options and innovative PFC ideas.

\section{PFC materials}

We touch on key safety issues for PFC options, grouped as $C, B e$, high $-Z$ refractory metals, and LMs.

Carbon: Even in the low fluence ITER physics phase, the C PFC tiles are responsible for about $2 \mathrm{~kg}-\mathrm{T}$ (1 kg-T co-deposited layer, $1 \mathrm{~kg}-\mathrm{T}$ with $\mathrm{C}$ dust). [1] All this surface tritium would be releasible in an air or steam ingress into the torus.

TABLE 2. PFC OPTIONS AND INNOVATIVE PFC IDEAS

Tiles attached to divertor and first wall For ITER, the divertor substrate is $\mathrm{Nb}, \mathrm{Cu}$, or Mo alloy; FW substrate is steel.

Carbon CDA ITER reference for physics phase

Beryllium Feasible for FW only

Tungsten Feasible for FW and divertor

Coatings applied to divertor and first wall substrate options the same as for tiles.

Beryllium CDA ITER alternative

Tungsten CDA ITER reference for technology phase

Tungsten ARIES-I and ARIES-III reference

Single material divertors Use a single material for both PFC surface material and for divertor substrate. Would still have a separate FW substrate.

Vanadium Thermophysical properties and material data base insufficient for ITER

Being considered for ITER

Single material first wall

Steel 316SS is the reference ITER FW. The ITER CDA c jvers this FW with C tiles (physics phase) and $W$ coating (technology phase).

Vanadium Material data base insufficient for ITER

Strong candidate for non-water-cooled DEMO

Liquid metal surface divertors Conventional FW still required.

Lithium Attractive candidate for ARIES-II

Gallium Being considered for ITER

Lead Less chemically reactive than $L i$ or $G a$

Innovative ideas potentially improving PFC options

Super-permeable vacuum ducts (increase the effective tritium burn fraction)

Self-pumping ducts (increase the effective tritiun burn fraction and ease vacuum pumping requirements)

Gas injection $=$ gaseous divertor (sti11 need a FW and divertor from elsewhere in this table). 
We expect this ingress this to be a frequent event, during both maintenance and operation. Also, with increasing fluence and associated radiation-induced traps, the tritium inventory will grow further. The tritium inventory associated with $C$ is a very strong argument against using it in ITER or DEMO. Metals seem to have far lower tritium PFC inventories. The highest current estimates we know are $180 \mathrm{~g}$ for Be [9] and $14 \mathrm{~g}$ for $\mathrm{W} .[4]$

C-steam reactions produce significant $\mathrm{H} 2$ gas during the high-frequency short-term transient triggered by an in-vessel LOCA. This C concern was resolved during the ITER CDA by limiting operating $C$ tile temperatures for $1 \%, 9 \%$, and $90 \%$ of the $\mathrm{FW}$ area to $1800 \mathrm{C}, 1500 \mathrm{C}$, and $1000 \mathrm{C}$.[1] The viability of this depends on validating ways to mechanically attach conductively-cooled tiles to the FW.

Besides the short-term $\mathrm{H} 2$ production during $\mathrm{C}$ tile cooldown, we now recognize that there would be additional $\mathrm{H} 2$ from long-term hot temperatures if the accident involved a major LOCA. A sequence of a LOCA in a major ex-vessel cooling component, failure of an internal component (in-vessel LOCA) with resulting steam contact with the PFC for long periods may give both the short-term and long-term hazards. Although this appears a low frequency scenario, it seems credible. once cooling was lost, in-vessel failures from temperature increases seem likely.

The combined short-term and long-term $\mathrm{H} 2$ production from $C$ depends on initial $C$ tile operating temperatures and the long-term LOCA time-temperature. Estimated values appear to extend up to $30 \mathrm{~kg}-\mathrm{H} 2$, above the $10 \mathrm{~kg}-\mathrm{H} 2$ goal.

Another $C$ critical issue is its need for high bakeout $(350 \mathrm{C})$ and conditioning $(250 \mathrm{C})$ temperatures. If done with hot water, there is a water/steam overpressure problem in the torus and radioactivity confinement. The CDA solution is to ban water above 150 C. [1] The viability of this solution depends on finding a credible method other than hot water.

Beryllium: Disruption tolerance of this PFC material seems slightly worse than for $C$, hence it must be considered a critical issue. However, experience in JET shows that disruptions (current decay rate, runaway electron current) are less severe in a Be machine than in a C machine. [11] Thus, on balance, Be seems preferred over $C$ from the disruption standpoint.

Beryllium is toxic. In a non-radioactive machine like present tokamaks, adding Be would be adding a significant hazard. (Although JET is showing that this can be handled.) In the radioactive ITER, $B e^{\prime} s$ chemical toxicity does not add to maintenance problems - all in-vessel maintenance will be remote. For ITER, Be chemical toxicity must be compared versus the high tritium inventory associated with $C$ and the high radioactivity generated in $W$.

During the short-term cooldown transient, Be-steam seems less hazardous than C-steam. We assume that with ITER heat loads, Be would be used as a thin coating. Thus, the operating Be temperatures would be much lower than operating $C$ temperatures. Thus, during the high-frequency short-term in-vessel LOCA, Be-steam hazards appear modest. The same Be-to-C comparison is true for air reactions. During a short-term transient (air or steam), the high tritium surface inventory on $C$ would be mobilized; ittle toxic Be would be mobilized (other than the dust).

However, for a long-term LOCA, Be-steam seems more hazardous than C-steam. (Again, a long-term major
LOCA will be far lower frequency than a short-term in-vessel LOCA or LOVA.) The long-term LOCA teniperatures are primarily fixed by the design and deciay heat of the blanket/shield and surrounding structures, not the PFC choice. Thus, the long-term LOCA temperatures would not vary much between Be or C PFC. Since the Be-steam reaction is faster than $C$-steam at a given temperature, Be-steain is more hazardous. Also, a long-term Be-steam (or Be-air) reaction would mobilize toxic Be0. $[5,6]$

High- $Z$ refractory metals: There are at least three options here - W coating ( $\mathrm{Nb}$ divertor substrate, steel FW substrate), solid $\mathrm{Nb}$ divertor with $\mathrm{Nb}$ coating on steel FW substrate, and solid Ta divertor with Ta coating on steel FW substrate.

The biggest CDA safety concern for $W$ is the high potential to mobilize activation products during long-term LOCAs.[1] Although new estimates of the $W$ activation inventory lower the estimated doses slightly, [12] this problem is still severe and must be considered a potential barrier to using $W$.

Our initial attempt to model the impact of PFC choice on disruption severity suggests a new critical issue for $W$ and related high- $Z$ options - more severe disruptions. We found the impurity density rate needed to produce the typical CDA current decay rate for $C$ (about $1 \mathrm{MA} / \mathrm{ms}$ ), and then assumed the same impurity atom density rate for other elements. Including the radiative properties of various materials, we find that $\mathrm{W}, \mathrm{Nb}, \mathrm{Mo}$, and Ta could produce disruptions much more severe than $C$. The maximum current decay rate could be 2-5 times faster than for C PFC, with correspondingly higher $E M$ forces. The runaway electron current could be 2 times higher than for c. [6] The viability of $W$ and other high-Z options depends on favorable resolution of this concern. (This model generally agrees with the JET finding that Be disruptions are less severe than (disruptions.)

For the single-material $\mathrm{Nb}$ or Ta divertor options, we currently estimate that the tritium permeation into the divertor will be at least 4 orders of magnitude higher than for other divertor options, potentially leading to intolerable costs to control tritium in the ITER water coolant. [6] This concern would be lessened if the coolant were something with easier tritiun removal, such as helium.

Liquid metal options: LM surface divertors/ limiters are alternatives to solid material divertors with the advantage that erosion losses and radiation damage problems are eliminated because of the continuously renewing surface.

Major LM options include Ga, GaInSn, Li, $17 \mathrm{Li} 83 \mathrm{~Pb}$, and $\mathrm{Pb}$. Ga and GaInSn have gained recent attention, al though the properties of $G a$ and its alloys are less well known than $\mathrm{Li}, 17 \mathrm{Li} 83 \mathrm{~Pb}$, and $\mathrm{Pb}$. LM choice should consider low atomic number, high boiling temperature, a large difference between melting and boiling points, high heat capacity, compatibility with structures, and the safety issues in Table 1.

Using the same model mentioned in the previous subsection, we estimate that disruptions with a $\mathrm{Li}$ divertor would be milder than $C$ and similar to Be. Like the other high- $Z$ elements, we estimate a high runaway electron current for $\mathrm{Pb}$. Unlike other high-Z elements, $\mathrm{Pb}$ shows a lower current decay rate than $\mathrm{C}$, due to its particular line-radiative properties. Our estimates for $\mathrm{Ga}$ suggest that its disruptions would be significantly worse than for $C$. 
Tritium inventory and permeation are important safety issues. The tritium solubility in $17 \mathrm{Li} 33 \mathrm{~Pb}$ is very low; the solubility in Li is several orders of magnitude larger. Tritium solubility in pure $\mathrm{Pb}$ is very low, lower than $17 \mathrm{Li} 33 \mathrm{~Pb}$. Our calculations suggest tritium permeation from $\mathrm{Pb}$ or $17 \mathrm{Li} 83 \mathrm{~Pb}$ divertor coolant systems into secondary water systenis may be 1-2 orders of magnitude higher than our goal of 1 $\mathrm{kCi} /$ day, without any credit for tritium permeation barriers. Correspondingly, the tritium inventory in $\mathrm{Pb}$ is below our goal.

Very little is known about the solubility of tritium in Ga and its alloys. Our preliminary estimates assuming high solubility suggest a high tritium inventory in $\mathrm{Ga}$, an order of magnitude higher than our goal, but with low permeation. Preliminary estimates with low solubility suggest tritium permeation into water 1-2 orders of magnitude higher than our 1 $\mathrm{kCi}$ day goal without credit for any permeation barriers, but with low tritium inventory. The tritium behavior in Ga and its alloys needs investigation.

One generic problem with LMs may be that the LM surface may not promote high particle recycling at the divertor. If so, the tritium burn fraction would drop, increasing the tritium inventories in most non-PFC fuel cycle components. This is less worrisome for $\mathrm{Pb}$ because of its low hydrogen solubility.

Lithium is low activation and $\mathrm{Pb}$ is high. [13] Gallium is intermediate, similar or even lower than steels.[13] Inclusion of activated corrosion products in highly-corrosive $\mathrm{Ga}$ may worsen the situation, a) though it cannot be worse than the activity of the surrounding structure.

Chemical reactivity of the $L M$ with water and air must also be considered. Lithium is very reactive with air, water, and concrete.[14] The Li-steam reaction again poses hydrogen production problem. To use Li safely in ITER (for either divertors or blanket test modules), key measures are inert gas zones around the torus (already planned in the CDA for other reasons) and minimizing the volume of $L M$. $17 \mathrm{LiB3Pb}$ reacts mildly with air, water, and concrete. [14] Pure $\mathrm{Pb}$ is even less reactive. Little is known quantitatively about Ga reactions with air and water, but we there is no reason to think it is more reactive than Li. Tests are needed to define Ga chemical reactivity.

\section{Safety characteristics of innovative PFC ideas}

We consider three innovative PFC ideas separate from major PFC options because each still needs a conventional PFC option to go with it. We see potential significant safety advantages from these innovative ideas - super-permeable vacuum ducts, helium self-pumping, and gaseous divertors.

Super-permeable vacuum ducts: If physics does not give us a burn fraction of $10 \%$ (or higher), engineering can help. With the ir colleagues, A. Livshits[15] and $S$. Cohen[16] suggest using permeation in the divertor/pumping duct walls to increase the effective tritium burn fraction. Tritium and deuterium would preferentially permeate through the walls to another duct to return to the plasma. Helium and impurities would go to vacuum pumps.

Self-pumping divertor/limiter: Two types of self-pumping systems have been studied, [17] one with plenum region trapping (called a slot divertor) and one with divertor plate trapping. In both designs. helium is pumped by trapping in freshly deposited layers of material that preferentially trap helium versus hydrogen. Proposed trapping materials include $\mathrm{V}, \mathrm{Fe}, \mathrm{Nb}, \mathrm{Mo}, \mathrm{Ta}$, and $\mathrm{Ni}$. This self-pumping simplifies design by reducing need for vacuum ducts, pumps, and penetration shielding, except a small startup system. Because the hydrogen will generally diffuse to the surface of the trapping layer and escape, tritium pumping, processiny and refueling may be significantly decreased, resulting in a lower tritium inventory. That is, the effective tritium burn fraction in the plasma is increased.

Gaseous divertors: Gas injection at the divertor has been proposed to lower heat loads on the solid (or liquid) divertor. This would improve divertor survivability during both normal and disruption conditions.

\section{Current Safety Ratings of PFC Options}

Fig. 1 shows our current safety and environmental rating of key PFC options relating to ITER. Ranking of PFC options in the cooling disturbances area depends strongly on the choice of substrate and coolant, which is beyond the scope of this paper.

Some ratings for materials would change somewhat if the material were used differently than indicated in Fig. 1. For example, consider Be FW tiles instead of Be coating. This would presumably improve disruption resistance to heat loads by having more sacrificial material and decrease tritium permeation into the coolant. It would worsen the accident energy release and toxin hazards by increasing the Be inventory.

Some ratings would change for a DEMO or fusion power plant. For example, the accidental energy release concerns for ITER are dominated by long-term water/steam reactions with the PFC material. Thus, the more reactive options ( $\mathrm{C}, \mathrm{Be}$, and $\mathrm{Li})$ look better in a machine without water coolant.

We think innovative approaches to PFC issues will improve the outlook. The fusion community must increase work on both advanced PFC options and on innovative ideas that may improve mainline options $(C$, $B e, W)$. The mainline PFC options have serious known issues. Advanced options may be better, but this cannot be guaranteed. Ideas like super-permeable vacuum ducts, self-pumping ducts, and gas ruffing (gaseous divertor) could improve all PFC options.

\section{Conclusions}

PFCs are well known as a critical design issue for ITER specifically and fusion generally. This is just as true for safety and environmental considerations as for other engineering and physics areas. Any viable strategy must include careful attention to the most critical safety and environmental issues in Table 3. No PFC candidate that we have examined is free of critical safety concerns. We recommend the following.

\section{Recommendations}

1. Increase PFC research by at least a factor of two. Target the increase toward advanced PFC options and resolution of critical issues for conventional options. Consider helium and LM coolants. Since divertors and disruptions are such a critical issue, existing tokamaks should do more to explore PFC options and disruption mitigation. We also need more divertor technology testing.

2. Produce a defendable worst-case set of disruption severity parameters (heat loads, EM forces, runaway electrons) for each PFC material. This must consider burn control equipment failures and accidental water/air ingress disruptions. 


\section{Disruption tolerance}

Disruption severity (PFC impact on disruptions)

Tritium inventory and permeation

Accidental energy release

Activation/toxin hazards

Cooling disturbances

System issues (bakeout, recycle)
C $\mathrm{Be} W \mathrm{Nb}$ Ta $\mathrm{Li}$ Ga Pb tiles coatings solids liquid metals attractive,
better than goals good, meets goals

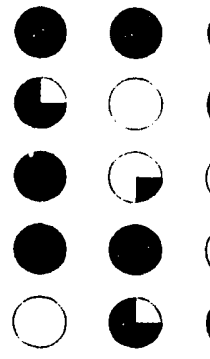

?

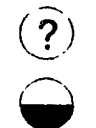

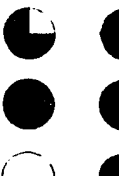
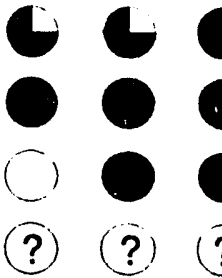

(?)

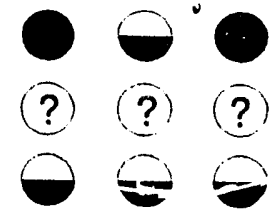

may be unacceptable

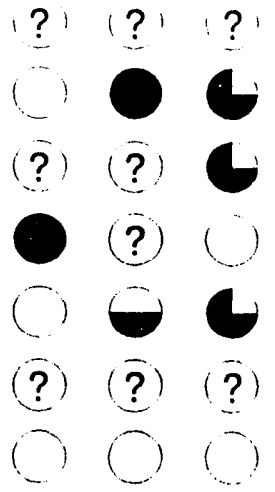

?

unknown

Fig. 1. Current safety and environmental rating of PFC options

TABLE 3. SUMMARY OF CRITICAL SAFETY ISSUES FOR PFC

\begin{tabular}{|c|c|c|}
\hline Material & Critical Issues & References \\
\hline Al1 & $\begin{array}{l}\text { Disruption tolerance, especially } \\
\text { those caused by air/steam ingress } \\
\text { or burn control equipment failure }\end{array}$ & $\begin{array}{ll} & \operatorname{CDA}[1] \\
\text { e } & \operatorname{new}[3,6]\end{array}$ \\
\hline Carbon & $\begin{array}{l}\text { High tritium surface inventory } \\
\text { H2 from LOCA }\end{array}$ & $\begin{array}{l}\operatorname{CDA}[1] \\
\operatorname{CDA}[1,5,6]\end{array}$ \\
\hline Beryllium & $\begin{array}{l}\text { Long-term } \mathrm{H} 2 \text { from LOCA } \\
\text { Be toxin volatility from LOCA }\end{array}$ & $\begin{array}{l}\text { new }[5,6] \\
\text { new }[5,6]\end{array}$ \\
\hline Tungsten & $\begin{array}{l}\text { High current decay rate and } \\
\text { runaway electron current during } \\
\text { disruptions } \\
\text { Activation volatility from LOSA }\end{array}$ & $\begin{array}{l}\text { new }[6] \\
\operatorname{CDA}[1]\end{array}$ \\
\hline Niobium/ta & $\begin{array}{l}\text { ntalum (single material divertors) } \\
\text { High current decay rate and } \\
\text { runaway electron current } \\
\text { during disruptions } \\
\text { Tritium permeation into coolant } \\
\text { High tritium inventory }\end{array}$ & $\begin{array}{l}\text { new }[6] \\
\text { new }[6] \\
\text { new }[6]\end{array}$ \\
\hline Liquid met & $\begin{array}{l}\text { al PFC } \\
\text { Tritium burn fraction and } H 3 \\
\text { uptake by the LM surface } \\
\text { Disruption severity for Ga } \\
\text { Chemical reactions of } L i\end{array}$ & $\begin{array}{l}\text { new }[6] \\
\text { new }[6] \\
\text { old[14] }\end{array}$ \\
\hline
\end{tabular}

3. Increase design attention to mitigating chemical reactions problems, specifically accidental energy release, activation/toxin mobilization. Design the shield, vacuum vessel, cryostat, and biological shielding to ensure that maximum long-term LOCA temperatures stay below $500 \mathrm{C}$. Keep the inert gas protection zone in ITER.

4. Increase safety research and design work so that PFC safety issues can be adequately resolved for ITER licensing. This includes activation product (and toxin) confinement research (mobilization, transport, filtration), which is not now in international ITER R\&D plans.

\section{Suggested strategy}

Our fifth recommendation is to carefully consider the proper strategy for ITER given serious uncertainties and critical issues that will not be resolved quickly. We offer the following strategy for fusion community consideration.

First, alter the ITER design to give absolute maximum flexibility for changing PFCs during the ITER lifetime. Ideally, one would not change the divertor (or other major in-vessel components) during the ITER

lifetime. Yet, the likelihood of having to do so seems high for two reasons. One, even the best pre-ITER R\&D will leave uncertainties regarding critical PFC performance that will only be resolved during ITER operation. We need flexibility to respond to surprises. Two, the frequency of in-vessel LOCA or LOVA seems high, requiring divertor repair or replacement. 
This flexibility strategy should include cassette divertor modules that come out quickly and easily as a single unit. The divertor module would incorporate the vacuum duct and divertor cooling lines and manifold as well as the divertor plates. This would allow faster changes and testing of innovative concepts. This maximum-flexibility approach must also include a way to remove PFC material from the FW. Both divertor cassettes and plasma-spray surfaces offer more flexibility and faster divertor change/repair than the half-million CDA reference $\mathrm{C}$-tiles.

To implement this strategy, we would select Be as the starting PFC material. We suggest Be over $C$ for two major reasons, both involving high-frequency accident concerns. One, Be appears to have an order of magnitude less tritium inventory than $C$. Worse, the $2 \mathrm{~kg}-T$ on $C$ seems particularly vulnerable during operation and maintenance. Two, Be appears to give less severe disruptions than $C$.

We suggest starting with Be over $W$ for two other major reasons. One, there is far more tokamak operating experience with Be than $W$. Two, we fear that $W$ disruptions may be far worse than for $C$ or $B e$.

As serious as the long-term LOCA issues involving $B e$ and $W$ appear to be, we still consider $C$ worse at present. The frequency seems high for mobilizing $2 \mathrm{~kg}-\mathrm{T}$ from $\mathrm{C}$ and short-term production of $\mathrm{H} 2$. The frequency of long-term LOCAs will be lower.

Even if the initial PFC material is $C$ or Be, design the structural supports for worse-than-C EM disruption forces to provide flexibility for non-Be PFC tests. Changing the divertor itself is easier than adding more structural support later.

During ITER operation, if the Be lifetime is too low because of disruption erosion (a major Be disadvantage), test high- $Z$ candidates, including $W$ coating on $\mathrm{Nb}$ divertor and a solid $\mathrm{Nb}$ divertor. If high-Z performance is superior and disruption severity is tolerable, change the PFC.

Second, design and pian for maximum PFC testing in ITER itself, both for ITER's sake and for DEMO's. Just as ITER must test blanket candidates for post-ITER machines, ITER must test PFC options for OEMO. Equally important, however, is the chance to test innovative PFC ideas or advanced divertor concepts on ITER with the hope to install them on ITER. We suggest carefully using at least one divertor cassette port as a PFC test station.

Above, we mention some innovative ideas - superpermeable membrane, He self-pumping, gaseous injection divertor - that will either increase the tritium burn fraction or reduce divertor heat loads. Ideally, these will receive sufficient R\&D to use one or more in the basic ITER design. If not, then we must test these innovative ideas during ITER operation and update the machine based on testing results.

Toward the end of ITER life (or earlier if Be and high- $Z$ options prove unacceptable), test advanced divertor coolants. This is more difficult than simply changing one or more divertor cassettes because one also changes the heat transport system. Test helium-cooled and LM-surface divertors (if the machine was not already built with one of these coolants).

\section{Acknowledgments}

We thank the various people who took the time to review drafts of this paper, especially S. Cohen, J. Perkins, and J. Raeder. This work is supported by the
U.S. Department of Energy, Office of Energy Research, Idaho Operations office, under DOE Contract No. DE-AC07-761D01570.

\section{References}

[1] J. Raeder and S. J. Piet, "ITER Safety Analyses," IAEA ITER Documentation Series No. 36, 1991.

[2] J. S. Herring, et al., "Activation Product Safety in the ARIES-1 Reactor Design," Fusion Technology, $\underline{19}(3$, part 2B), May 1991, pp. 1386-1391.

[3] S. J. Piet, "ITER Safety Challenges and Opportunities," this conference.

[4] R. A. Anderl, et al., "Tritium Transport and Trapping in Polycrystalline Tungsten," 4th Topical Meeting on Tritium Technology in Fission, Fusion, and Isotopic Applications, Albuquerque, NM, Sept. 29 - Oct. 4, 1991.

[5] G. R. Smolik, et a1., "Implications of Beryllium: Steam Interactions in Fusion Reactors," 5th International Conference on Fusion Reactor Materials, Clearwater, FL, Nov. 17-22, 1991.

[6] S. J. Piet, et al., "Safety and Environmental Information for Plasma-Facing Component Options for ITER and Beyond," in preparation.

[7] C. Flanagan, editor, ITER Design Information Document, ITER-90-1, 1990.

[8] B. J. Merrill and S. C. Jardin, "Coolant Ingress Induced Disruption Calculations for ITER," Fusion Technology, 19(3, part 2B), May 1991, pp. $1278-1283$

[9] T. Kuroda, G. Vieider, et al., "ITER Plasma Facing Components," IAEA ITER Documentation Series No. 30, 1991.

[10] 0. F. Holland, "Cost Optimization of Tritium Control Systems," Nuclear Technology/Fusion, $\&(2$ part 3), September 1983, pp. 1127-1130.

[11] G. R. Harris, Comparisons of the Current Decay During Carbon-Bounded and Beryllium-Bounded Disruptions in JET, JET-R(90)01, December 1990.

[12] S. J. Piet, "New Tungsten Dose Values for ITER," letter SJP-31-91, May 16, 1991.

[13] S. J. Piet, E. T. Cheng, and L. J. Porter, Accident Safety Comparison of Elements to Define Low Activation Materials, EGG-FSP-8552, July, 1989.

[14] S. J. Piet, et al., "Liquid Metal Chemical Reaction Safety in Fusion Facilities, "Fusion Engineering and Design, 5,1987 , pp. 273-298.

[15j A. I. Livshits, et a]., "Helium Exhaust Enrichment by a Membrane System in the Divertor of the ITER, " Experts' Working Session on the Physics of Alternative Power and Particle Control Concepts, ITER-IL-PC-4-0-8, October 1990.

[16] S. A. Cohen, "Helium Exhaust Enrichment by Selective Permeation (and Related Tricks), "ITER Workshop on Advanced Divertor Concepts, October 1990.

[17] J. N. Brooks, et al., Self-Pumping Impurity Control Systems for $1 N 10 R$, ANL/FPP/TM-212, January 1987. 

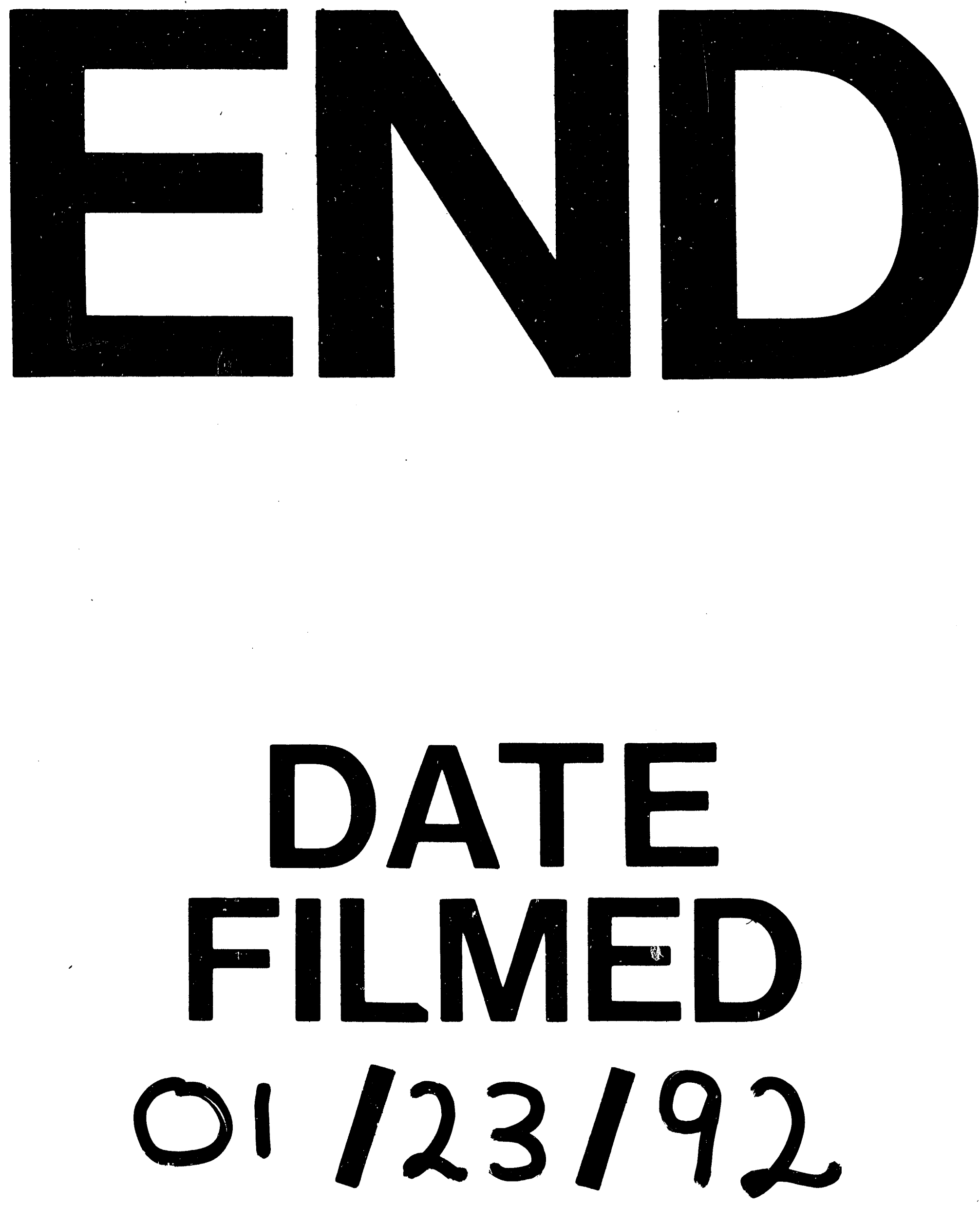


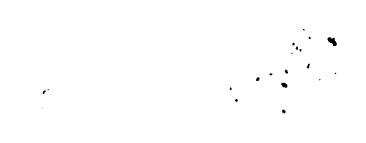

